Egyptian

Orthodontic Journal

\title{
INTEGRITY OF DENTAL ARCH FORM: A REVIEW
}

\author{
Zuhair A. Murshid ${ }^{*}$
}

\section{ABSTRACT:}

The orthodontic literature shows diversity in adopting a reliable and definitive method for determining the shape and dimension of the dental arch form. Several visual, linear, geometric, and mathematical methods were employed in order to sort the form of the arch wire to fit a given dental arch. The consensus among researchers and orthodontists is that there is no general shape for the arch form and that the original mandibular arch form should be preserved. This concept has been translated through several vendors (Ortho CADs) for fabrication of the treatment arch wire for a patient, using pretreatment study cast. In addition, the Insigna and Sure Smile systems produced arch wires made-up for each patient. The method of Andrews and Andrews (2000) to determine the mandibular individual arch form (WALA ridge) seems promising and a recent study showed a positive correlation between this method and arch form shaping of treatment arch wire [jad1]s.

\section{INTRODUCTION}

From an orthodontic point of view, the shape and size (dimension) of the dental arch form have a significant inference in diagnosis and treatment planning, influencing the tooth width/arch perimeter relationship, function, esthetics and post-treatment stability. Researchers have expended considerable effort to describe the dental arch form. Several methods are available to describe the dental arch form and to fabricate the clinical arch wire. Nevertheless, the stability of posttreatment dental arch form remains a dilemma for both the orthodontist andthe patient.

\footnotetext{
${ }^{*} \mathrm{KAU}$, Jeddah, KSA
} 
Historically, the orthodontists, anatomists and Prosthodontists who have investigated dental arch forms have been concerned with shape and size. Black ${ }^{(1)}$ described arch form as simi-ellipse. Bonwell ${ }^{(2)}$ developed an equilateral triangle with inter-condyler distance as a base and apex in between the central incisors. Hawley ${ }^{(3)}$ modified this concept by using the widths of the six anterior teeth arranged in an arc of a circle and the buccal segments extending along a straight line, and namedit as the Bonwell-Hawleyarch form. Angle ${ }^{(4)}$ recognized the importance of arch shape and form and described the line of occlusion as the key of proper occlusion, stating "The best balance, the best harmony and the best proportions of the mouth in its relation to the other features, requires that there should be a full complement of teeth and that each tooth should be made to occupy its normal position-normal growth". Tweed ${ }^{(5)}$ advocated extraction of teeth to maintain post-treatment stability. Lundstrom ${ }^{(6)}$ recognized that concept, and proposed the basal bone theory, stating, "Dental arch form follows the configuration of the supporting bone". Later, $\mathrm{Chuck}^{(7)}$ believed that the correct determination of the patient's arch form is the base of treatment arch wire shape, thus leading to successful treatment and stability. He proposed a visual method to describe the dental arch forms as ovoid, round, tapered and squared. Later, Boone ${ }^{(8)}$ based his template on the original shape of arch form using inter-canine and inter-molar widths.

The latter concepts prompted orthodontists to carry out several studiesin order to find the best fitting curve to describe the shape of dental arch form through application of linear (arch width, depth and size) and geometric mathematical models. Some authors preferredto use the catenary curve (McConnail \& Sichar ${ }^{(9)}$, Musich and Ackerman $^{(10)}$.Other researchers suggested the parabola, ellipse, trifocal ellipse, cubic spline and polynomials (Felton et al. ${ }^{(11)}$, Brader $^{(12)}, \mathrm{Lu}^{(13)}$, Mills and Hamilton ${ }^{(14)}$, Currier ${ }^{(15)}$, Huddart ${ }^{(16)}$, Biggerstaff ${ }^{(17)}$, Pepe ${ }^{(18)}$, Hechter $^{(19)}$, White ${ }^{(20)}$, Begole ${ }^{(21)}$, Jones and Richmond ${ }^{(22)}$,Ferrario et al ${ }^{(23)}$ and Alharbi et $\mathrm{al}^{(24)}$. Other workers employed a more complex concept.Braun et al. ${ }^{(25)}$ and Noroozi et al ${ }^{(26)}$ useda beta function, in order to find a reliable method to describe arch form using different mathematical models. White ${ }^{(20)}$ felt that, there were disagreements among 
Egyptian

Orthodontic Journal

researchers regarding the best fit of these formulae. He conducteda study to compare the closeness of the fit of different curve fitting formulae on untreated cases. He found that no universal ideal arch form seemed to be applicable and that the majority of dental arch forms were asymmetrical. Despite the ample efforts aimed at applying a variety of these research methods to describe dental arch form using mathematical models, they did not address an anatomical reference to draw from the correct clinical dental arch form.

Early on, Andrews ${ }^{(27)}$ established the six keys of occlusion and developed the straight wire concept; this has put orthodontic mechanics into a higher level and it may be considered that the second era of orthodontic philosophy had started after Angle's edgewise method to achieve more stable occlusion. Andrews considered the lower dental arch form as the seventh key of class I occlusion. Therefore the era of preformed arch wire based on normal occlusion had just started. Later on, Roth ${ }^{(28)}$, Ricketts ${ }^{(29)}$ and Alexander ${ }^{(30)}$ followed that concept and based their preformed arch wires on finished cases. This resulted in True arches and Pentamorphic arches respectively. However, with the availability of different shapes and sizes of commercially preformed arch wires, Felton et al ${ }^{(9)}$ realized the difficulty of generalizing the adaptation of these treatment preformed arch wires to the dental arch form. They compared ten brands of preformed arch wires with thirty normal dental arches. They found that less than $50 \%$ of the samples fit only two brands. They concluded that these preformed arch forms tended to fall into three categories: ovoid, tapered and square shapes. Moreover, Braun et $\mathrm{al}^{(25)}$, compared sixteen titanium arch wire brands with the mean shape of normal dental arches. His results reinforced a similar finding to that of Felton et $\mathrm{al}^{(9)}$ in that the brand arch wires were wider than normal arches. Raberin et $\mathrm{al}^{(31)}$ and Trivino et $\mathrm{al}^{(32)}$ believed that, within a population, different shapes and sizes could be observed. They decided to follow Ricketts' concept of pentamorphic arches, and classified dental arch forms into five and twenty-three shapes respectively, based on normal occlusion. However, human arch forms are variable and are not thought to follow such a rigid geometric pattern. It seems more logical to describe dental arch forms in simple shape forms instead of complicated 
Egyptian

Orthodontic Journal

mathematical formulae. Furthermore, these studies analyzed the arch form from anatomic and anthropologic perspectives to evaluate its implications during orthodontic therapy and its modifications after treatment.

In addition, some studies have highlighted differences in arch forms and sizes among different racial groups (e.g., Nojima et $\mathrm{al}^{(33)}$ ). Nonetheless, Bishara et $\mathrm{al}^{(34)}$ added that, because of the great variability in individual arch forms, a single arch form cannot be used in all orthodontic cases. To verify that Oda et al ${ }^{(35)}$ compared 20 commercially available arch wire forms with 30 mandibular dental casts made of untreated subjects with the ideal occlusion. They found that the variation inthe current preformed arch wires does not correspond entirely with the various arch forms in the group with ideal occlusion. On the other hand, Raberin et al ${ }^{(31)}$, Proffit ${ }^{(36)}$, Ricketts ${ }^{(29)}$ and Brader ${ }^{(12)}$ believed that the lower arch in a normal individual dictates the upper arch. The basal bone theory which is originally developed by Lundstrom ${ }^{(6)}$, was adopted by Andrew and Andrews ${ }^{(37)}$. They presented a method to determine the anatomical dental arch form called the WALA ridge (the most prominent point on the soft tissue ridge immediately occlusal to the mucogingival junction) which is correlated to the shape of arch wire formulated from the midpoints of the facial axis of clinical crowns(FA). The recent study by Ronay et $\mathrm{al}^{(38)}$ examined the usefulness of that ridge in determining the size and shape of the dental arch form using three-dimensional scans of Class I mandibular casts. They reported that there is a positive correlation between the two and that the WALA ridge might be a useful reference to predict patients' dental arch form. Furthermore, they suggested that all basal and dental arches (WALA ridge and FA) should be individually derived to draw a conclusion regarding the dimensions of the individualized dental arch form. This approach may save efforts for better stability of the treatment outcome. In that respect, Gupta et al ${ }^{(39)}$ translated the WALA ridge and FA as a digital model to cone-beam computed tomography images. This may aid in determining the exact position of basal bone landmarks and define the final shape of the dental arch form in order to obtain maximum long-term stability. 
Egyptian

Orthodontic Journal

This concept has been translated through several vendors such as Ortho CADs for fabrication of treatment arch wire for a patient using a pretreatment study cast. In addition, the Insigna and Sure Smile systems produce arch wires made-up for each patient.

On the other hand, many other factors, such as maxillary expansion and orthodontic extraction of teeth and their effect on post treatment stability could not be included in this review, but the etiological factors of malocclusion may play a role in post-orthodontic stability; genetic, periodontal health conditions and developmental factors:

1. Genetic factor: in a study of genetic influence on dental arch form, Cassidy et al ${ }^{(40)}$ stated, "Little is known of the factors controlling dental arch size and shape". They found that arch size and shape were subjected to environmental influences at a greater extent than to heredity, as the orientation of the teeth(rather than their locations in supporting bone) are found to be affected primarily by the environment. Nonetheless, it could be speculated that local environmental factors control tooth angulations but specific influences remain elusive ${ }^{(41)}$. While Henrikson et $\mathrm{al}^{(42)}$ in a longitudinal study found a significant increase in inter-molar width and a reduction inarch depth. They also reported a significant correlation between changes in the mandibulararch form and increased irregularity of lower incisors. In addition, Lee ${ }^{(43)}$ reported similar findings. These findings should direct attention towards the need forbetter understanding of the extrinsic factors that modulate arch size and shape during development ${ }^{(36)}$. Some researchers (Proffit ${ }^{(36)}$, Bjork and Skieller ${ }^{(44)}$, Proffit et al ${ }^{(45)}$, Solow et al ${ }^{(46)}$ and Vargervik et al ${ }^{(47)}$ ' have claimed that variability in eruptive paths of the teeth, growth of the supporting bones, and movement of the teeth after emergence due to habits and unbalanced muscular pressures, all contribute to variation in arch size and shape.

2. Facial type has concerned a number of researchers. Ricketts ${ }^{(29)}$ Ricketts et $\mathrm{al}^{(48)}$ De la Cruz et $\mathrm{al}^{(49)}$, Braun et $\mathrm{al}^{(25)}$, and Enlow and Hans ${ }^{(50)}$,have reported that a correlation can exist between facial types and dental arch forms. A long-faced individual usually has narrower transverse dimensions (dolichofacial) and a short-faced individual has wider transverse dimensions (brachyfacial). In addition, Nasby et $\mathrm{al}^{(51)}$ 
Egyptian

Orthodontic Journal

found that the maxillary and mandibular arch circumference and the mandibular intermolar width were greater in subjects with low MP - SN (mandibular plane to sellanasion)angles when compared with those with high MP-SN angles. Because dental arch width is associated with gender and facial vertical morphology, it is essential during orthodontic treatment to use customized pretreatment arch wires to fitthearch form and size of each patient. Christie ${ }^{(52)}$ confirmed that, when treating a patient, the norms used should reflect the differences associated with the various facial patterns and sex.

3. Periodontal health: Maintenance of periodontal health is very important during orthodontic treatment planning, thus patients have to maintain good oral hygiene during treatment. In successful orthodontic treatment, we opt to have good functioning occlusion and with no breakdown of the periodontium. Yared et al ${ }^{(53)}$ noticed a periodontal effect that resulted from excessive proclination of lower incisors and reported significant recession associated with proclination in excess of 95 degrees to the mandibular plane. Again, tissue type plays a bigger role in such recession. However, Gkantidis et al ${ }^{(54)}$ said, "In modern clinical practice, the contributions of the orthodontist, the periodontist and the general dentist are essential for an optimized treatment outcome".

4. Gender: an article by Forster et $\mathrm{al}^{(55)}$ pointed out that the dental arches of males grow wider than those of females. In both males and females, there was a tendency for the MP-SN angle to increase as arch width decreased. Inter molar widths increased in both genders but they continued to increase from 12 to 17 years in males but not in females ${ }^{(56)}$.Odajima ${ }^{(57)}$ and Tsai ${ }^{(58)}$ also found a similar tendency in both Japanese and Chinese, respectively. Cassidy et $\mathrm{al}^{40)}$ confirmed the former findings and stated that, "Arch dimensions are significantly larger in boys, mediolaterally and anteroposteriorly than in girls. A sex difference is largely established prior to the onset of the adolescent growth spurt".

The maintenance of lower arch integrity has been considered one of the most important factors leading to successful orthodontic treatment. Evidence for maintaining lower arch integrity has come from studies at the University of Washington and elsewhere, which showed strong links between long-term stability and preservation of the original $\operatorname{arch}$ form ${ }^{(8,11,25,27,29-39)}$. 
From a clinical perspective, there are some recommendations that may help both the orthodontist and the patient to accomplish a successful treatment result:

1. During treatment planning:

a. We should consider arch form as one of our treatment objectives.

b. Always preserve the original arch form.

c. Do not expand the lower inter-canine width beyond its limit.

d. Balance between upper arch expansion and esthetics.

e. Maintain good periodontal health throughout treatment.

f. Avoid overexpansion of arches.

2. When selecting arch wire:

a. Choose an arch form close to patients arch form, especially when using stainless steel TMA wires. Use the WALA ridge as a reference.

b. Unlike stainless steel and B-Titanium wires, 0.016 and less of nickel titanium arch wires had minimal effect on arch form.

c. Consider the patient's gender, ethnicity and facial type.

d. Maintenance of the selected arch form is mandatory.

e. Use a study cast and a symmetry chart.

f. Always coordinate upper and lower arch wires.

3. During retention:

a. Keep the integrity of the mandibular arch as an objective to achieve post-retention stability.

b. Expansion of the inter-canine width was shown to be unstable.

c. Permanent retention for an expanded lower arch should be planned. 
Egyptian

Orthodontic Journal

\section{CONCLUSION}

1. As a concept, the majority of clinicians preserve original arch form.

2. WALA ridge points can be useful in the predetermination of dental arch form. ${ }^{(38)}$

3. The highly significant correlation of WALA and FA(point midpoint of the facial axis of clinical crown width in inter-canine and intermolar areas) proves that assessments of WALA points enable the prediction of corresponding FA values and the clinical arch form. $(38,39)$

4. The mandibular model with all the permanent teeth present provides the best basis for construction of a correct or physiologic arch form.

5. Expanded mandibular arch form by appliance therapy could not be stable, except forlingually tilted canines and up righted incisors. ${ }^{(49)}$

6. Arch wire templates might require not only shape selection but also a wider size variation for clinical application, which are not available today. ${ }^{(35)}$

7. Most orthodontic techniques recommended the shapes and the variations of tapered, ovoid and square as Ortho forms, I, II, III $(7,11,33)$

8. The range of selection in the current commercially available performed or orthodontic arch wire forms does not appropriately cover the required natural human diversity. ${ }^{(33,35)}$

9. Preformed arch wires are made using various geometric or computergenerated data; the fit to an individual mandibular model is highly variable. ${ }^{(11,20,33,35)}$

10. The contributing genetic factor to the dental arch form, should lead to the consideration of the patient's ethnic background when selecting performed arch wire blanks. ${ }^{(33)}$

11. If there is no uniformity concerning the buccal corridor, increasing the arch width will have various impacts on post-treatment stability. ${ }^{(25)}$ 
Egyptian

Orthodontic Journal

\section{REFERENCES}

1. Black GV: descriptive anatomy of the human teeth. Fifth Edition, Philadelphia.

2. Bonwell WGA: geometric and mechanical laws of articulation. Transaction Odontometric Society: 119-133. Pennsylvania.

3. Hawley CA: Determination of normal arch and its application to orthodontics. Dental Cosmos, 1905: 47:541-552.

4. Angle EH: treatment of malocclusion of the teeth. Ed.7 SS White Dental manufacturing; 1907: 21-24. Philadelphia.

5. Tweed CH. Clinical orthodontics.Vol. 1. St Louis: Mosby; 1966.

6. Lundstrom A 1: malocclusion of teeth regarded as a problem in connection with the apical base. International Journal of Orthodontics, 1925; 11: 315-326.

7. Chuck GC: Ideal arch form. Angle Orthodontics; 1934; 4: 312-327.

8. Boone GN: Archwires designed for individual patients. Angle Orthod.1963; 33: 178-185.

9. McConail MA, Scher EA: the idealform of the human dental arcade with some prosthetic application. Dental Record; 69:285-302.

10. MusichDR, Ackerman JL : The catenometer: a reliable device for estimating dental arch perimeter. Am J Orthod 1973; 63: 366-375.

11. Felton J M, Sinclair P M, Jones D L, Alexander R G: A computerized analysis of the shape and stability of mandibular arch form. A J O D Orthopedics, 1987; 92: 478-483.

12. Brader $A C$ : Dental arch form related with intraoral forces: $P R=C$. Am J Orthod., 1972;61:541-561.

13. $\mathrm{Lu} \mathrm{KH:} \mathrm{An} \mathrm{orthogonal} \mathrm{analysis} \mathrm{of} \mathrm{the} \mathrm{form,} \mathrm{symmetry} \mathrm{and}$ asymmetry of the dental arch. Arch Oral Biol 1966; 11: 1057-1069.

14. Mills LF, Hamilton PM: Epidemiological studies of malalignment, a method for computing arch circumference. Angle Orthod 1965; 35: 244-248 
Egyptian

Orthodontic Journal

15. Currier JH: A computerized geometric analysis of human dental arch form. Am J Orthod 1969; 59:164-178.

16. Huddart A: The application of computer study of maxillary arch dimensions. Br Dent J 1971;130: 397-404.

17. Biggerstaff RH: three variations in dental arch form estimated by a quartic equation. J Dent Res 1972; 51: 1509-1513.

18. PepeSH: polynomial and catenary curve fit to human dental arches. J Dent Res 1975; 54:1124-1132.

19. Hechter FJ: Symmetric and dental arch form of orthodontically treated patients. J Can Den Assoc 1978; 44:173-184.

20. White L: Individualized ideal arches. J Clin Orthod 1978;12:779-787

21. Begole EA: Application of the cubic spline function in the description of dental arch form. J Dent Res 1980; 59:1549-1556

22. Jones ML, Richmond S : An assessment of the fit of a parabolic curve to pre and post treatment dental arches. Br J Orthod 1989; 16: 85-94.

23. Ferrario VF, Sforza C, Miani A Jr, Tartaglia G: Mathematical definition of the shape of dental arches in permanent healthy dentition.Eur J Orthod 1994; 16:287-294.

24. Alharbi S, Alkofide E, Almadi A: Mathematical analysis of dental arch curvature in normal occlusion. Angle Orthod 2008; 78: 281-287.

25. Braun S, Hnat WP, Fender DE, Legan HL: The form of the human dental arch. Angle Orthod 1998;68: 29-36.

26. Noroozi H, Nik TH, Saeeda R: The dental arch form revisited. Angle Orthod 2001; 71:386-389.

27. Andrews LF: Straight wire: the concept and appliance. San Diego: L Wells; 1989. P.159.

28. Roth RH: The straight wire appliance 17 years later. J Clin Orthod 1987; 21: 632-642. 
Egyptian

Orthodontic Journal

29. Rickitts RM: Design of arch form and details for bracket placement. Denver: Rocky Mountain Orthodontics; 1979.

30. Alexander RG. The Vari-Simplex discipline: Part 1. Concept and appliance design. J ClinOrthod.1983; 17:380-392.

31. Raberin M: Dimensions and form of dental arches in subjects with normal occlusions.Am J OrthodDentofacialOrthop 1993;104: 67-72.

32. Trivino $\mathrm{T}$, vilella OV: Forms and dimensions of the lower dental arch. Rev Soc Bras Orthodon 2005; 5:19-28.

33. Nojima K, McLaughlin RP, Isshiki Y, Sinclair PM: A comparative study of Caucasian and Japanese mandibular clinical arch form. Angle Orthod 2001; 71: 195-200.

34. Bishara SE, Chadra JM, Potter RE: stability of intercanine width, overbite and overjet correction. Am J Orthod 1973; 63:588-595.

35. Oda S, Arai K, Nakahara R: Commercially available arch wire forms compared with normal dental arch forms in Japanese population. Am J OrthodDentofacialOrthop 2010; 137(4):520-527.

36. Proffit W R.: Equilibrium theory revisited. Angle Orthodontics.1994; 64:407-414.

37. Andrews LF, Andrews WA: The six elements of orofacial harmony. Andrews J 2000; 1:13-22.

38. Ronay V, Miner RM, Will LA, Arai K: Mandibular arch form: The relationship between dental and basal anatomy. Am J Orthod D Orthopedics. 2008;134(3):430-438

39. Gupta D, Miner M, Arai K, Will LA: Comparison of the mandibular dental and basal arch forms in adults and children with Class I AND Class II malocclusions. Am J Orthod D Orthopedics.2010;138:10-11.

40. Cassidy KM, Harris EF, Tolley EA, Keim RG. Genetic influence on dental arch form in orthodontic patients. Angle Orthod. 1998 Oct; 68(5):445-54

41. Proffit WR: On the aetiology of malocclusion. $\mathrm{Br} \mathrm{J}$ Orthod 1986;13:1-11. 
Egyptian

Orthodontic Journal

42. Henrikson J, Persson M, Thilande B: Long term stability of dental arch form in normal occlusion from 13 to 31 years of age. Eur J orthod 2001 Feb;23(1):51-61.

43. Lee RT: Arch width and form: A review. Am J Orthod Dento facial Orthop 1999; 115(3): 305-313.

44. Bjork A, Skieller V: Growth in width of the maxilla studied by the implant method. Scand J Plast Reconstr Surg. 1974; 8:26-33.

45. Proffit WR, Fields HW, Nixon RM: Occlusal forces in normal and long face adults. J Dent Res. 1983; 62:566-571.

46. Solow B, Siersbaek-Nielsen S, Greve E.: Airway adequacy, head posture, and craniofacial morphology. Am J Orthod. 1984;86:214-223.

47. Vargevik K, Miller AJ, Chierci G, Harvold E, Tomer BS: Morphologic response to changes in neuromuscular patterns induced by altered modes of respiration. Am J Orthod. 1984;85:115-124.

48. Ricketts RM, Roth RH, Chaconas SJ, Schulhof RJ, Engle GA: Orthodontic diagnosis and planning. Rocky Mountain Data Systems, Denver. 1982.

49. De La Cruz A, Sampson P, Little R, Artun J, Shapiro P: Long-term changes in arch form after orthodontic treatment and retention. A J O D Orthopedics, 1995; 107: 518-530.

50. Enlow D, Hans MG: Essentials of facial growth. WR Saunders Company, Philadelphia.

51. Nasby JA, Isaacson RJ, Worms FW, Speidel TM Orthodontic extractions and the facial skeletal pattern. Angle Orthod. 1972 Apr;42(2):116-22.

52. Christie TE. Cephalometric patterns of adults with normal occlusion. Angle Orthod. 1977 Apr;47(2):128-35.

53. Yared KF, Zenobio EG, Pacheco W. Periodontal status of mandibular central incisors after orthodontic proclination in adults. Am J Orthod Dento facial Orthop. 2006 Jul;130(1):6.e1-8. 
54. Gkantidis N, Christou P, Topouzelis N: The orthodontic-periodontic interrelationship in integrated treatment challenges: a systematic review.20101; 37(5):377-390.

55. Forster CM, Sunga E, Chung CH: Relationship between dental arch width and vertical facial morphology in untreated adults. Euro J Orthod 2008; 30:288-294.

56. Sinclair P, Little R: Maturation of untreated normal occlusions. Am J Orthod. 1983;83: 114-123.

57. Odajima T: A longitudinal study on growth and development of dental arches of primary, mixed and permanent dentitions. Shikwa Gakuho 1990 mar;90(3):396-409.

58. Tsai HH: A computerized analysis of dental arch morphology in early permanent dentition. ASDC J Dent Child 2002; 69(3):259-265 